\title{
A Pharmacogenetic Investigation of Intravenous Furosemide in Decompensated Heart Failure: A Meta-Analysis of 3 Clinical Trials
}

\author{
Simon de Denus, BPharm, MSc, PhD ${ }^{1,2,3}$, Jean L Rouleau, MD ${ }^{1,4}$, Douglas L. Mann, MD ${ }^{5}$, \\ Gordon S. Huggins, MD ${ }^{6}$, Thomas P. Cappola, MD, ScM7 ${ }^{7}$, Svati H. Shah, MD, MHS ${ }^{8}$, \\ Julianna Keleti, $\mathrm{PhD}^{9}$, Yassamin Feroz Zada, $\mathrm{MSc}^{2}$, Sylvie Provost, $\mathrm{MSc}^{2}$, Amina Bardhadi, \\ $\mathbf{P h D}^{2}$, Michael S. Phillips, $\mathbf{P h D}^{2}$, Valérie Normand, $\mathbf{M S c}^{2}$, lan Mongrain, $\mathbf{M S c}^{2}$, and Marie- \\ Pierre Dubé, PhD ${ }^{1,2,4}$
}

${ }^{1}$ Research Center, Montreal Heart Institute, Montreal, Qc ${ }^{2}$ Université de Montréal BeaulieuSaucier Pharmacogenomics Center, Montreal. Qc ${ }^{3}$ Faculty of Pharmacy, Université de Montréal, Montreal, Qc ${ }^{4}$ Medicine, Université de Montréal, Montreal, Qc ${ }^{5}$ Washington University School of Medicine, St. Louis, Missouri ${ }^{6}$ Tufts Medical Center, Boston, Massachusetts ${ }^{7}$ University of Pennsylvania, Philadelphia ${ }^{8}$ Division of Cardiology, Duke University School of Medicine, Durham, NC ${ }^{9}$ National Heart, Lung, and Blood Institute, Bethesda, Maryland.

\section{Abstract}

We conducted a meta-analysis of pharmacogenomic substudies of three randomized trials conducted in patients with decompensated heart failure (HF) which were led by National Heart Lung and Blood Institute (NHLBI)-funded HF Network to test the hypothesis that candidate genes modulate net fluid loss and weight change in patients with decompensated HF treated with a furosemide-based diuretic regimen. Although none of the genetic variants previously shown to modulate the effects of loop diuretics in healthy individuals were associated with net fluid loss after 72 hours of treatment, a set of rare variants in the $A P O L 1$ gene, which codes for apolipoprotein L1 ( $P=0.0005$ in the random effects model) was associated with this endpoint. Moreover, a common variant in the multidrug resistance protein-4 coding gene ( $A B C C 4$,

\footnotetext{
Users may view, print, copy, and download text and data-mine the content in such documents, for the purposes of academic research, subject always to the full Conditions of use:http://www.nature.com/authors/editorial_policies/license.html\#terms

Correspondence: Simon de Denus, Montreal Heart Institute, 5000 Belanger Street, Montreal, Quebec H1T 1C8, Canada. Tel.: 514 376-3330. Fax: 514 376-1355. simon.dedenus@icm-mhi.org.

Author Contributions

Simon de Denus designed the substudy, interpreted the results and wrote the first draft of the manuscript.

Marie-Pierre Dubé designed the substudy, analyzed the data and wrote the manuscript.

Douglas L. Mann, Gordon S. Huggins, Thomas P. Cappola, Svati Shah, Julianna Keleti designed the substudy and contributed to critical review and writing of the manuscript.

Yassamin Feroz Zada, Sylvie Provost, Amina Bardhadi analyzed the data and wrote of parts the manuscript.

Michael S. Phillips, Valérie Normand and Ian Mongrain designed the custom panels and generated genetic data. Ian Mongrain wrote parts of the manuscripts. Michael S. Phillips contributed to the design of the substudy. Valérie Normand contributed to critical review and writing of the manuscript.

Conflict of Interest/Disclosures

Simon de Denus has received compensation from Servier for service as a consultant, was supported through grants from Pfizer, AstraZeneca, Roche, and Novartis, and has received payment for lectures including service on speaker bureaus from Pfizer. Svati Shah holds a patent on an unrelated finding and has received grant support from Pfizer, Liposcience and Bristol-Meyers Squibb.
} 
rs 17268282) was associated with weight loss with furosemide use $(P=0.0001)$. Our results suggest that both common and rare genetic variants modulate the response to a furosemide-based diuretic regimen in patients with decompensated HF.

\section{Keywords}

furosemide; loop diuretics; meta-analysis; pharmacogenomics; genetics and pharmacogenetics; decompensated; heart failure

\section{INTRODUCTION}

Loop diuretics, and in particular furosemide, are the most effective agents for the management of signs and symptoms of fluid overload in patients with heart failure (HF). Indeed, through their blockade of the sodium-potassium-chloride co-transporter in the thick ascending limb of the loop of Henle, loop diuretics induce a natriuretic effect that leads to the excretion of 20 to $25 \%$ of the filtered sodium. ${ }^{1}$ Given their rapid onset of action, intravenous loop diuretics are an essential component of the pharmacological treatment of patients with decompensated HF to relieve the signs and symptoms of fluid overload. ${ }^{2}$ However, there exists a considerable heterogeneity in the treatment response to loop diuretic therapy. Understanding whether genetic mechanisms, in addition to clinical factors, might influence the response to diuretics could help optimize treatment strategies.

Despite the fact that approximately ninety percent of patients admitted with decompensated HF receive an intravenous diuretic, ${ }^{3}$ there are no pharmacogenomics studies published in this patient group. Indeed, previous studies have primarily focused on small numbers of healthy volunteers treated with torsemide, ${ }^{4-8}$ while there is only limited data with the more commonly-used loop diuretic furosemide. ${ }^{5,9}$ Also, these studies were limited to common variants in a few genes coding for renal sodium reuptake transporters, including those coding for the targets of loop (SLC12A1) and thiazide diuretics (SLC12A3).

We sought to further investigate the impact of genetic variations in these and other candidate genes on the efficacy of the loop diuretic furosemide in patients with decompensated HF. To do so, we conducted pharmacogenomic substudies of patients enrolled in three randomized trials conducted by the National Heart Lung and Blood Institute (NHLBI) funded HF Network (HFN): the Diuretic Optimization Strategies Evaluation in Acute HF, (DOSE), CARdiorenal REScue Study in Acute Decompensated HF (CARRESS) and the Renal Optimization Strategies Evaluation in Acute HF (ROSE). To test the hypothesis that candidate genetic markers would be associated with the degree of fluid loss and amount of change in weight with furosemide therapy, we elected to conduct a meta-analysis of patients enrolled in these three trials.

\section{METHODS}

\section{Overview of the trials}

We conducted pharmacogenomics substudies of participants who provided informed consent to participate in the Genomic/Pharmacogenomic substudies of the DOSE (ClinicalTrials.gov 
identifier: NCT00577135), CARRESS (NT00608491) and ROSE (CT01132846) trials which investigated treatment strategies in patients with decompensated HF. The eligibility criteria, methods (summarized in the supplementary material) and primary results for these trials have been reported previously. ${ }^{10-12}$ In each of these studies, the response to diuretics were collected and included daily fluid balance and weight for at least 72 hours following randomization. ${ }^{10-12}$ Patients who were randomized to the ultrafiltration arm in CARRESS, or who did not receive IV furosemide in the first 24 hours of the studies were excluded from this analysis, leaving 364 patients in the analysis (DOSE: 60; CARRESS: 42; ROSE: 262; see supplementary materials for details).

\section{Genetic analyses}

All genetic analyses were performed in GLP-environment at the Université de Montréal Beaulieu-Saucier Pharmacogenomics Centre, located at the Montreal Heart Institute (Montreal, Canada). Details regarding sample management, DNA isolation and genotyping are provided in the supplementary materials. The genotyping strategy for the HFN was to use a variety of genotyping platforms including commercial and custom assays which were performed on all participants across all clinical trials. ${ }^{10-12}$ Genotyping included broad-based genotyping approaches (Illumina HumanOmni2.5-8 BeadChip, Illumina HumanExome v1.0 Beadchip, Sequenom iPLEX ${ }^{\circledR}$ ADME PGx Panel) and complementary custom Sequenom candidate gene panels. For the current substudy, to maximize statistical power, we limited our investigations to common and rare genetic variants from these platforms in 19 candidate genes that were selected based on their potential role to modulate the pharmacodynamics and pharmacokinetics of furosemide or renal function (Table 1). ${ }^{1,13}$ Following the quality checks and genetic data cleanup process (supplementary materials), 2040 SNPs from these genes were included in the analyses.

\section{Statistical analyses}

Study endpoints-The primary objective of this pharmacogenetic meta-analysis was to test whether genetic variants previously shown to modulate the diuretic effects of loop diuretics (SLC12A3 rs1529927, the SCNN1B2 haplotype [rs152728, rs152745, rs238547] and $S C N N 1 G$ rs5723 and rs5729) ${ }^{5}$ are associated with net fluid loss (the total fluid output over 72 hours minus the total fluid input over 72 hours in $\mathrm{mL}$ ) of a diuretic strategy based on intravenous furosemide at 72 hours after randomization in patients with decompensated HF.

The secondary objectives of this analysis were to explore the association between other variants included in the 19 selected candidate genes (Table 1) and net fluid loss, as well as amount of weight loss (in kilograms [kg]) at 72 hours. The focus and conclusions of this substudy are related to the associations observed in the meta-analyses conducted, not the individual studies. Because of the differences between the study populations, we based our interpretations on the results of the random effects models.

Genetic association analyses-Single-variant analyses were limited to the 1683 SNPs having a minor allele frequency (MAF) greater than 0.01 . The normality assumption of the residuals was tested by using the Shapiro-Wilk statistic and by inspection of the histogram and of the QQ plot of the residuals. A general linear model (GLM) was performed for all 
end points in all studies separately while adjusting for covariates in each model (see supplementary material for covariates). To detect outliers, a linear regression model was fitted including covariates into the analysis model but excluding the genetic variables and externally studentized residuals were tested. Two outliers were removed in each end point.

An additive genetic test was used and genotypes were coded as $0,1,2$ according to the copy of the minor allele. Haplotype probability for the primary SNPs of interest were obtained using proc HAPLOTYPE in SAS. Rarer variants (MAF lower than 0.05), were analyzed jointly using the Sequence kernel Association Test (SKAT). ${ }^{14}$ Only genes with minor allele counts of 5 or more were considered for SKAT analysis. All analyses were conducted using SAS 9.4 (SAS Institute Inc., Cary, NC, USA), PLINK version 1.07 or the SKAT R-package. The analyses performed to adjust for covariates and sensitivity analyses are described in the supplementary materials.

Meta-analysis and significant threshold-For the single variant analyses, the endpoints were analysed using a linear regression model using ordinary least squares for each study separately, and these results were used to perform a fixed and a random metaanalysis using METASOFT software. ${ }^{15}$ The heterogeneity was tested between the studies using the $Q$ test and $I$-square. For the rare variants meta-analyses, we used the general framework for meta-analysis proposed by Lee et al. ${ }^{16}$ The proposed method calculates score statistics and aggregates them across studies. The framework is based on study-specific summary statistics for each region and is flexible enough to accommodate a range of heterogeneity of genetic effects across studies. We used the MetaSKAT package (version 0.40, R3.1.1) provided by the same authors to calculate a multi-marker score statistics for fixed-effect meta-analysis and a multi-marker score statistics for random-effects metaanalysis.

Statistical analyses performed were two-sided and the significance threshold was adjusted for the multiple testing of SNPs. For the primary endpoint, this threshold was set as at 0.008 (Bonferroni correction 0.05/6 SNPs). For all other single-variant analyses, the significance threshold was established using the number of independent tests $\left(\mathrm{M}_{\mathrm{eff}}\right)$ estimated using the method of Gao et al. ${ }^{17}$ to $\mathrm{M}_{\mathrm{eff}}=191$. The significance threshold was set to $0.00026 \approx$ $(0.05 / 191)$ for secondary single variant analyses. For the rare variants analyses, 46 gene sets were analysed by MetaSKAT including 21 intergenic sets. For those analyses, the significance threshold was set to 0.00109 (Bonferroni correction 0.05/46).

\section{Ethical considerations}

All studies were approved by the local institutional review board (IRB), and all patients provided written informed consent to participate in the clinical studies. Moreover, in centers electing to participate in the Genomic/pharmacogenomic substudy of the clinical trials, the substudy was approved by the IRB at each site. Patients taking part of the HFN trials were offered the option of participating in the genetic sub-study. To participate in the substudy, patients provided written informed consent. 


\section{RESULTS}

\section{Study populations}

Baseline characteristics of the three study populations are included in Table 2. A majority of participants were Caucasians, while ischemic heart disease was the most common cause of HF. On average, CARRESS patients presented with a higher mean weight and body mass index at baseline compared to participants from the other two studies. As expected per study inclusion criteria, CARRESS patients presented with more severe renal dysfunction at baseline than patients in ROSE or DOSE, the latter presenting the least severe renal dysfunction at baseline.

Participants in CARRESS received, on average, a higher dose of loop diuretic prior to the hospitalisation, a greater dose of IV loop diuretic in the 24 hours prior to randomization. The use of metolazone was much higher in CARRESS participants than in the other two studies. In regards to the endpoints investigated in the studies, net fluid loss and weight loss appeared to be greater in CARRESS than in the other two studies.

Primary objective-None of the six primary variants in genes $S C N N 1 G, S C N N 1 B$ or $S L C 12 A 3$ or their haplotypes (data not shown) were significantly associated with net fluid loss in the meta-analysis of the studies, nor in the individual studies (Table 3). Indeed, all p values were well above our pre-established threshold of $0.008(0.05 / 6)$.

Secondary analyses-The ten strongest associations in the random effects model for net fluid loss and for amount of weight loss for single variant meta-analyses are represented in Tables 4 and 5, respectively. In regards to fluid loss at 72 hours after randomization, none of the single variant tests from the 19 candidate gene tested reached our pre-defined statistical threshold $(P<0.00026)$ in the meta-analyses. Five of the top ten genetic associations observed in the random effects meta-analyses for this endpoint were from SNPs located in the $A B C C 4$ gene ( $P$ from 0.0066 to 0.0012 ), and one genetic association on the $W N K 1$ gene approached statistical significance $(P=0.0009)$. The $A B C C 4$ gene codes for the multidrug resistance protein-4 (MRP4), which is an ATP-binding cassette transporter implicated in the luminal efflux of furosemide from proximal tubular epithelial cells.

Of the rare variants gene-based meta-analyses performed for the endpoint of fluid loss, one reached statistical significance after correcting for multiple testing (0.00109) of rare variants. This gene set is located in the APOL1 gene (Table 6), which codes for apolipoprotein L1, and this association was statistically significant in both the random and fixed effects models ( $P=0.0005$ and $P=0.0008$, respectively). The rare variants are located in the sixth and seventh (last) exons of $A P O L 1$, and in the fifth and sixth introns. All ten coding variants are described as missense mutations based on ENSEMBL. This gene set includes rs 73885319 and rs60910145, two missense variants which have extensively associated with the risk of renal dysfunction in African-Americans. ${ }^{18}$ Moreover, rs 148296684 was characterised as deleterious by SIFT $^{19}$ and probably damaging by POLYPHEN $2,{ }^{20}$ while rs 73885316 , rs150685787 and rs138178894 were described as possibly damaging by POLYPHEN2. None of these rare variants were in significant linkage disequilibrium (LD) with the two common variants (rs713753, rs4419330) in APOL1 presented in Table 4 (all $\mathrm{r}^{2} \leq 0.65$ ). 
In regards to weight loss, one genetic association reached statistical significance in the metaanalysis. This variant, an intronic SNP in the $A B C C 4$ gene (rs17268282; minor allele frequency: 0.0598), reached statistical significance after adjusting for multiple comparisons ( $P=0.0001$ in both the fixed and random effect models). Carriers of the A allele experienced a greater amount of weight loss and thus an increased response to furosemide (Supplementary Table 2). Looking at individual studies, although the impact of the variant reached statistical significance only in the ROSE study (Table 4), no significant heterogeneity in the meta-analysis was observed $\left(\mathrm{I}^{2}=0\right.$, Q value $=1.52 ; P=0.48$; see supplementary Figure for forest plot). The association between rs17268282 did not reach statistical significance with regards to the net fluid loss endpoint $(P=0.12)$. Of note however, nine of the top ten associations with weight loss were located in the $A B C C 4$ gene or implicated variants near this gene. None of these other eight SNPs was in LD with rs 17268282 (all $\mathrm{r}^{2} \leq 0.35$ ). This limited LD between $\mathrm{rs} 17268282$ and these top associations in the random effects model is represented in Figure 1. None of the variants we genotyped in $A B C C 4$ that presented a high level of $\mathrm{LD}\left(\mathrm{r}^{2}>0.8\right)$ were coding.

As with fluid loss, none of the six primary SNPs was associated with weight loss at 72 hours $(P>0.2$ for all, data not shown). Finally, none of the rare variants in the SKAT metaanalyses reached statistical significance after correcting for multiple testing (data not shown). The $A P O L 1$ region described earlier presented $P$ values of association of 0.04 and 0.14 in the fixed and random effects model respectively.

\section{Caucasian subgroup}

Additional analyses were performed in the Caucasian subgroup, although this considerably limited the sample size ( $\mathrm{n}=265$ across all studies). MAF for each population are described in Supplementary Table 3, and illustrates that the minor allele changed in some cases between populations. For common variants, the top ten associations in the overall population were repeated for both endpoints (see Supplementary Tables 4 and 5) in Caucasians only. For fluid loss, no association reached the significance threshold in the Caucasian subgroup. In regards to weight loss, although no association reached our pre-established threshold, the signal observed for the $A B C C 4$ variant rs 17268282 was still apparent in the fixed and random effects models $\left(P=0.0009\left[\mathrm{I}^{2}=12.82\right.\right.$, $\mathrm{Q}$ value $\left.=2.29 ; P=0.32\right]$ and 0.03 , respectively).

In regards to the $A P O L 1$ region, it is well-known that the rs73885319 and rs60910145 variants are part of a locus in the last exon of the gene which is associated with an increased risk of renal dysfunction in African-American patients, ${ }^{18}$ but these variants are extremely rare in Caucasians. ${ }^{21}$ As seen in Table 6, these two variants were also extremely rare in the Caucasians of the current studies. Nonetheless, a trend was still observed for the association between this gene set and fluid loss in the random model $(P=0.0023)$, while the fixed effects model remained below the significance threshold of the rare variants analysis ( $P=$ $0.00102)$. 


\section{Metolazone use}

In order to control for the potential effect of metolazone, we conducted additional analyses that took into consideration the use of this agent in the 72 hours following randomization for rs17268282 and the rare-variant $A P O L 1$ locus. The association between rs17268282 and weight loss remained significant in the overall population $(P=0.0001$ for both the fixed and random effects models; $\mathrm{I}^{2}=0, \mathrm{Q}$ value $=1.69 ; P=0.43$ in the fixed effects model), but this association did not reach statistical significance in the Caucasian subgroup ( $P$ value for fixed and random effects: 0.001 and 0.0842 , respectively).

In regards to the $A P O L 1$ region and fluid loss, the association remained below our significance threshold for rare variants (0.00109) in the random effects meta-analysis conducted in the entire population $(P=0.0008)$, was of borderline significance in the fixed effects model in the entire population $(P=0.0019)$, as well as both models limited to only Caucasians (fixed: $P=0.0013$, random: $P=0.002$ ).

Finally, when limiting all the previous statistical models related to the APOL1 region to only patients who had complete data over 72 hours $(\mathrm{n}=342)$, all models (fixed and random), including the Caucasian subgroup, were consistent with our main observation, although, given the smaller sample size, these were of borderline significance ( $P$ values 0.002 to 0.005).

\section{DISCUSSION}

The current investigation explored the pharmacogenomics of intravenous furosemide-based diuretic regimens by conducting a meta-analysis of three substudies from randomized controlled trials conducted by the HFN Network in patients with decompensated HF. Despite representing, to our knowledge, the largest pharmacogenomic study of a loop diuretic, the results of our primary analyses did not validate previously reported associations in healthy individuals between three candidate genes and loop diuretic response. ${ }^{5}$

Nevertheless, in our secondary analyses of additional candidates, we observed that rare variants in a region of the apolipoprotein-1 coding gene, $A P O L 1$, which has been associated with risk of chronic renal disease in African-Americans, ${ }^{18}$ was associated with fluid loss following 72 hours of treatment with an intravenous furosemide-based diuretic treatment. Furthermore, we observed that an intronic variant in the MRP-4 coding gene, $A B C C 4$, was associated with diuretic-induced weight loss. Also, five of the top ten genetic associations observed in the random effects meta-analyses for fluid loss and nine of the top ten genetic associations observed for weight loss were from SNPs located in or near the $A B C C 4$ gene. The associations were apparent after adjusting for possible confounders. Furthermore, when limiting our analyses to the Caucasian subgroup, the observed effects remained, although they did not reach our pre-defined thresholds in all models.

Our results are at odds with those of an investigation of 97 healthy Caucasians that found that the variants we also tested in the $S L C 12 A 3, S C N N 1 B$ and the $S C N N 1 G$ genes were associated with multiple phenotypes of diuretic response, including diuresis and sodium excretion. ${ }^{5}$ Multiple factors can explain these discrepancies. First, our investigation focused on patients with decompensated HF while this study evaluated normal individuals. Thus, for

Pharmacogenomics J. Author manuscript; available in PMC 2017 March 24. 
these specific genetic variants, one could argue that in patients with decompensated HF, interindividual variability in diuretic response may be less dependent on genetic factors than the amount of fluid overload ${ }^{22}$ or disease-related variables, including neurohormonal activation and altered hemodynamics. In other words, the potential impact of these variants in healthy individuals may be minimized in the extreme conditions of decompensated HF. Indeed, such patients likely presented a wide variety of underlying causes for the aggravation of their HF and HF results in a number of neurohormonal (activation reninangiotensin-system, ${ }^{23}$ adrenergic ${ }^{24}$ and vasopressin systems, ${ }^{25}$ ) cardiac (decreased cardiac output $^{26}$ ) and renal changes (such as increased sodium reabsorption in the proximal nephron ${ }^{27}$ ) that can modulate diuresis or sodium retention. Renal dysfunction may be a particularly important modulator of inter-individual variability in loop diuretic effectiveness. ${ }^{22}$ Indeed, to reach their target and exert their effects, loop diuretics are actively secreted in the lumen of the renal tubule. ${ }^{1,28}$ Thus, given the severity of renal dysfunction in many patients from the current populations, the reduced secretion of furosemide in the proximal tubule cells could become a major contributor to the heterogeneity in its reaching its site of action, the Na-K-Cl transporter, in the loop of Henle, ${ }^{29}$ and thus, to produce its natriuretic effect. ${ }^{30}$ Indeed, existing evidence suggest that in patients with severe renal dysfunction, only one-fifth to one-tenth of a loop diuretic may be secreted in tubular fluid as in healthy individuals. ${ }^{29,30}$

Second, contrary to the previous report in which patients received fixed, single doses of loop diuretics, ${ }^{5}$ in the current study, diuretic strategies used were more heterogeneous between patients and between studies and could be adjusted based on clinical response. One could also argue that in clinical practice, careful monitoring and therapy adjustments by the treating clinician may compensate for genetically-driven differences in diuretic response. Finally, in the previous study, ${ }^{5}$ no adjustment had been made for multiple testing while we made these adjustments. Lack of adjustment could have increased the risk of false-positive findings in the previous study.

Apolipoprotein-1, which is coded by the APOL1 gene, is a minor apolipoprotein component of HDL, which is primarily synthesized in the liver. ${ }^{31}$ Little is known about the functional role of apolipoprotein 1 in kidney diseases, other than it is expressed in the kidney. ${ }^{31}$ Thus, as underlined by others, one cannot exclude that the associations observed could be the result of linkage with other causal genetic variants. ${ }^{18}$ Common variants in the APOL1 gene have previously been associated with chronic kidney diseases in a wide variety of black patient populations, including chronic kidney diseases attributed to hypertension. ${ }^{18,32,33}$ In Caucasians, because these variants are rare, their impact is uncertain. Nevertheless, in our study, using SKAT, ${ }^{14}$ we found that this region was associated with net fluid loss after 72 hours of treatment, even when limiting our meta-analysis to Caucasians. Importantly, all of our analyses were adjusted for baseline renal function. Our interpretation of this association is limited by the fact that SKAT analyses provide an aggregate of individual score test statistics of SNPs in the region, thus, we cannot conclude as to the individual impact of the mutations located in this genomic region on the response to furosemide. Few pharmacogenomics studies have focused on APOL1. Data from the African American Study of Kidney Disease and Hypertension (AASK) showed that the benefit of ACE inhibitors were independent of $A P O L 1 .{ }^{18}$ Further research is required to validate the association we 
observed and decipher by what mechanisms $A P O L 1$ could modulate the diuresis induced by furosemide. Should the role of apolipoprotein 1 in modulating diuresis be confirmed, it could become a novel pharmacological target in the management of fluid overload.

MRP-4 is expressed in a variety of tissues including the kidney, the lung, the liver, the brain, lymphocytes and platelets. ${ }^{34}$ Given this ability to efflux its substrates outside of cells, MRP-4 has been a focus of research in oncology as a potential contributor to anticancer drug resistance. ${ }^{35}$ The substrates of MRP-4 include the antineoplastic agents 6-mercaptopurine and 6-thioguanine. ${ }^{35}$ Data are more limited in the area of cardiovascular pharmacogenomics and MRP-4, but furosemide is a known substrate of MRP-4. ${ }^{36-38}$ In the kidneys, MRP-4 is located in the proximal tubule apical membrane of epithelial cells ${ }^{34}$ and may contribute to the secretion of furosemide in the lumen. ${ }^{38}$ A study in MRP-4 knock-out mice showed that the renal clearance of furosemide and hydrochlorothiazide was significantly reduced compared to the wild-type mice. ${ }^{38}$ Thus, one would expect that such reduced secretion or efflux in the lumen may reduce the efficacy of furosemide in carriers of loss-of-function variants. Accordingly, the association we observed between rs17268282 and weight loss is consistent with a potential role for genetic variants in the MRP-4-coding gene ABCC4 in modulating the response to furosemide. Should these findings be validated in other cohorts, they could help clinicians personalize the initial furosemide dosing in patients presenting with decompensated HF.

Nevertheless, we must exert caution in the interpretation of this result. Indeed, the SNP is located in a non-coding region of $A B C C 4$, thus, the functional explanation behind the association is not immediate. Moreover, the fact that the association between this SNP and net fluid loss was not significant further clouds the exact underpinning of this observation. This limitation is also true for our observation regarding the APOL 1 locus and fluid loss which did not reach statistical significance for weight loss. Nevertheless, one could argue that in critically ill patients ${ }^{39}$ many factors influence fluid balance, some of which were not evaluated in our study, and the importance of which can vary markedly over the 72 hour period of the study. ${ }^{39,40}$ Moreover, previous data from the DOSE trial have demonstrated that these markers of decongestion, fluid loss and weight loss, are only modestly correlated. ${ }^{41}$

Our investigation has unique features. First, it is the first to investigate the pharmacogenomics of a loop diuretic in patients with decompensated HF. Second, the response phenotypes of interest to loop diuretics were collected as part of three carefully conducted clinical trials. Third, the use of multiple platforms enabled a comprehensive investigation of both rare and common variants in 19 candidate genes. Fourth, our metaanalysis represents the largest sample size for a pharmacogenomic study of a loop diuretic.

\section{Limitations}

Despite being the largest sample size studied to date, it remained too small to consider the use of a hypothesis-free genome-wide approach. Furthermore, because patients received diuretics other than furosemide, this could have reduced our ability to find genetic associations with the effects of furosemide. To minimize this, we controlled for the use of other loop diuretics by adjusting for furosemide equivalent dosing. Furthermore, we 
controlled for metolazone as a sensitivity analysis, to avoid over fitting of our initial models. We did not adjust for the use of other thiazides diuretics, because their use was too infrequent. Another limitation that requires mention is that, given the acuteness and intricacy of the disease being investigated, we cannot exclude that our results may be reflective of other factors which we were unable to control for.

Finally, given the complexity of the pharmacology of loop diuretics and the decompensated HF syndrome, it is unlikely that interindividual differences in the response to loop diuretics can be comprehensively explained by a limited number of genetic or clinical factors. To decipher this complexity, large cohorts of patients will be required and thus the creation of collaborations to further advance our understanding of the response to diuretics and other HF drugs appears necessary. Such consortia have enabled a more comprehensive and detailed understanding of other multiple complex traits and drug response and these can ultimately lead to the development of comprehensive genetic risk scores which encompass multiple genetic variants. ${ }^{42}$

In conclusion, our results indicate that previously reported genetic variants found to be associated with the response to loop diuretics in normal individuals did not have a major impact on the responsiveness to a furosemide-based diuretic regimen in patients presenting with decompensated HF. Although speculative, our findings would suggest that, contrary to healthy individuals, the clinical characteristics related to HF severity (e.g. LVEF, renal dysfunction, neurohormonal activation) may represent more important determinants of diuretic response than these genetic variants in the subset of patients with decompensated HF. We did, however, find that genetic variants in the $A P O L 1$ and $A B C C 4$ genes appear to modulate the diuretic effects of furosemide, but these findings require further investigation.

\section{Supplementary Material}

Refer to Web version on PubMed Central for supplementary material.

\section{Acknowledgements}

Julianna Keleti is a Clinical Trials Specialist at the National Heart, Lung, and Blood Institute, National Institutes of Health, Bethesda, MD. Simon de Denus holds the Université de Montréal Beaulieu-Saucier Chair in Pharmacogenomics.

\section{References}

1. Brater DC. Pharmacology of diuretics. Am J Med Sci. 2000; 319:38-50. [PubMed: 10653443]

2. Heywood JT, Fonarow GC, Costanzo MR, Mathur VS, Wigneswaran JR, Wynne J. High Prevalence of Renal Dysfunction and Its Impact on Outcome in 118,465 Patients Hospitalized With Acute Decompensated Heart Failure: A Report From the ADHERE Database. J Card Fail. 2007; 13:422430. [PubMed: 17675055]

3. Fonarow GC, Heywood JT, Heidenreich PA, Lopatin M, Yancy CW. Temporal trends in clinical characteristics, treatments, and outcomes for heart failure hospitalizations, 2002 to 2004: findings from Acute Decompensated Heart Failure National Registry (ADHERE). Am Heart J. 2007; 153:1021-1028. [PubMed: 17540205]

4. Vormfelde SV, Toliat MR, Schirmer M, Meineke I, Nurnberg P, Brockmoller J. The polymorphisms Asn130Asp and Val174Ala in OATP1B1 and the CYP2C9 allele *3 independently affect torsemide 
pharmacokinetics and pharmacodynamics. Clin Pharmacol Ther. 2008; 83:815-817. [PubMed: 18043684]

5. Vormfelde SV, Sehrt D, Toliat MR, Schirmer M, Meineke I, Tzvetkov M, et al. Genetic variation in the renal sodium transporters $\mathrm{NKCC} 2, \mathrm{NCC}$, and $\mathrm{ENaC}$ in relation to the effects of loop diuretic drugs. Clin Pharmacol Ther. 2007; 82:300-309. [PubMed: 17460608]

6. Vormfelde SV, Schirmer M, Toliat MR, Meineke I, Kirchheiner J, Nürnberg P, et al. Genetic variation at the CYP2C locus and its association with torsemide biotransformation. Pharmacogenomics J. 2007; 7:200-211. [PubMed: 16969365]

7. Vormfelde SV, Schirmer M, Hagos Y, Toliat MR, Engelhardt S, Meineke I, et al. Torsemide renal clearance and genetic variation in luminal and basolateral organic anion transporters. Br J Clin Pharmacol. 2006; 62:323-335. [PubMed: 16934049]

8. Vormfelde SV, Engelhardt S, Zirk A, Meineke I, Tuchen F, Kirchheiner J, et al. CYP2C9 polymorphisms and the interindividual variability in pharmacokinetics and pharmacodynamics of the loop diuretic drug torsemide. Clin Pharmacol Ther. 2004; 76:557-566. [PubMed: 15592327]

9. Costanzo MR, Johannes RS, Pine M, Gupta V, Saltzberg M, Hay J, et al. The safety of intravenous diuretics alone versus diuretics plus parenteral vasoactive therapies in hospitalized patients with acutely decompensated heart failure: A propensity score and instrumental variable analysis using the Acutely Decompensated Heart Failure National Registry (ADHERE) database. Am Heart J. 2007; 154:267-277. [PubMed: 17643575]

10. Felker GM, Lee KL, Bull DA, Redfield MM, Stevenson LW, Goldsmith SR, et al. Diuretic strategies in patients with acute decompensated heart failure. N Engl J Med. 2011; 364:797-805. [PubMed: 21366472]

11. Bart BA, Goldsmith SR, Lee KL, Givertz MM, O'Connor CM, Bull DA, et al. Ultrafiltration in decompensated heart failure with cardiorenal syndrome. N Engl J Med. 2012; 367:2296-2304. [PubMed: 23131078]

12. Chen HH, Anstrom KJ, Givertz MM, Stevenson LW, Semigran MJ, Goldsmith SR, et al. Low-dose dopamine or low-dose nesiritide in acute heart failure with renal dysfunction: the ROSE acute heart failure randomized trial. JAMA. 2013; 310:2533-2543. [PubMed: 24247300]

13. Hasannejad H, Takeda M, Taki K, Shin HJ, Babu E, Jutabha P, et al. Interactions of human organic anion transporters with diuretics. J Pharmacol Exp Ther. 2004; 308:1021-1029. [PubMed: 14610216]

14. Wu MC, Lee S, Cai T, Li Y, Boehnke M, Lin X. Rare-variant association testing for sequencing data with the sequence kernel association test. Am J Hum Genet. 2011; 89:82-93. [PubMed: 21737059]

15. Han B, Eskin E. Random-Effects Model Aimed at Discovering Associations in Meta-Analysis of Genome-wide Association Studies. Am J Hum Genet. 2011; 88:586-598. [PubMed: 21565292]

16. Lee S, Teslovich Tanya M, Boehnke M, Lin X. General Framework for Meta-analysis of Rare Variants in Sequencing Association Studies. Am J Hum Genet. 2013; 93:42-53. [PubMed: 23768515]

17. Gao X, Starmer J, Martin ER. A multiple testing correction method for genetic association studies using correlated single nucleotide polymorphisms. Genet Epidemiol. 2008; 32:361-369. [PubMed: 18271029]

18. Parsa A, Kao WH, Xie D, Astor BC, Li M, Hsu CY, et al. APOL1 risk variants, race, and progression of chronic kidney disease. N Engl J Med. 2013; 369:2183-2196. [PubMed: 24206458]

19. Ng PC, Henikoff S. Predicting Deleterious Amino Acid Substitutions. Genome Res. 2001; 11:863874. [PubMed: 11337480]

20. Adzhubei I, Jordan DM, Sunyaev SR. Predicting functional effect of human missense mutations using PolyPhen-2. Curr Protoc Hum Genet. 2013; 76:7.20.1-7.20.41.

21. O'Seaghdha CM, Parekh RS, Hwang SJ, Li M, Köttgen A, Coresh J, et al. The MYH9/APOL1 region and chronic kidney disease in European-Americans. Hum Mol Genet. 2011; 20:2450-2456. [PubMed: 21429915]

22. Gottlieb SS, Stebbins A, Voors AA, Hasselblad V, Ezekowitz JA, Califf RM, et al. Effects of nesiritide and predictors of urine output in acute decompensated heart failure: results from 
ASCEND-HF (acute study of clinical effectiveness of nesiritide and decompensated heart failure). J Am Coll Cardiol. 2013; 62:1177-1183. [PubMed: 23747790]

23. Good J, Frost G, Oakley CM, Cleland JG. The renal effects of dopamine and dobutamine in stable chronic heart failure. Postgraduate Med J. 1992; 68(Suppl 2):S7-S11.

24. Guazzi MD, Agostoni P, Perego B, Lauri G, Salvioni A, Giraldi F, et al. Apparent paradox of neurohumoral axis inhibition after body fluid volume depletion in patients with chronic congestive heart failure and water retention. Br Heart J. 1994; 72:534-539. [PubMed: 7857735]

25. Bichet DG, Kortas C, Mettauer B, Manzini C, Marc-Aurèle J, Rouleau JL, et al. Modulation of plasma and platelet vasopressin by cardiac function in patients with heart failure. Kidney Int. 1986; 29:1188-1196. [PubMed: 3528612]

26. Mettauer B, Rouleau JL, Bichet D, Juneau C, Kortas C, Barjon JN, et al. Sodium and water excretion abnormalities in congestive heart failure. Determinant factors and clinical implications. Ann Intern Med. 1986; 105:161-167. [PubMed: 2873771]

27. Volpe M, Magri P, Rao MA, Cangianiello S, DeNicola L, Mele AF, et al. Intrarenal determinants of sodium retention in mild heart failure: effects of angiotensin-converting enzyme inhibition. Hypertension. 1997; 30:168-176. [PubMed: 9260976]

28. Cox ZL, Lenihan DJ. Loop Diuretic Resistance in Heart Failure: Resistance Etiology-Based Strategies to Restoring Diuretic Efficacy. J Card Fail. 2014; 20:611-622. [PubMed: 24879974]

29. Shankar SS, Brater DC. Loop diuretics: from the Na-K-2Cl transporter to clinical use. Am J Physiol Renal Physiol. 2003; 284:F11-F21. [PubMed: 12473535]

30. Brater DC. Diuretic therapy. N Engl J Med. 1998; 339:387-395. [PubMed: 9691107]

31. Ma L, Shelness GS, Snipes JA, Murea M, Antinozzi PA, Cheng D, et al. Localization of APOL1 Protein and mRNA in the Human Kidney: Nondiseased Tissue, Primary Cells, and Immortalized Cell Lines. J Am Soc Nephrol. 2014; 26:339-348. [PubMed: 25012173]

32. Freedman BI, Langefeld CD, Lu L, Palmer ND, Smith SC, Bagwell BM, et al. APOL1 associations with nephropathy, atherosclerosis, and all-cause mortality in African Americans with type 2 diabetes. Kidney Int. 2014; 87:176-181. [PubMed: 25054777]

33. Langefeld CD, Divers J, Pajewski NM, Hawfield AT, Reboussin DM, Bild DE, et al. Apolipoprotein L1 gene variants associate with prevalent kidney but not prevalent cardiovascular disease in the Systolic Blood Pressure Intervention Trial. Kidney Int. 2014; 87:169-175. [PubMed: 25029429]

34. van Aubel RA, Smeets PH, Peters JG, Bindels RJ, Russel FG. The MRP4/ABCC4 gene encodes a novel apical organic anion transporter in human kidney proximal tubules: putative efflux pump for urinary cAMP and cGMP. J Am Soc Nephrol. 2002; 13:595-603. [PubMed: 11856762]

35. Gradhand U, Kim RB. Pharmacogenomics of MRP Transporters (ABCC1-5) and BCRP (ABCG2). Drug Metab Rev. 2008; 40:317-354. [PubMed: 18464048]

36. El-Sheikh AA, van den Heuvel JJ, Koenderink JB, Russel FG. Effect of hypouricaemic and hyperuricaemic drugs on the renal urate efflux transporter, multidrug resistance protein $4 . \mathrm{Br} \mathrm{J}$ Pharmacol. 2008; 155:1066-1075. [PubMed: 18724382]

37. Uchida Y, Kamiie J, Ohtsuki S, Terasaki T. Multichannel liquid chromatography-tandem mass spectrometry cocktail method for comprehensive substrate characterization of multidrug resistance-associated protein 4 transporter. Pharm Res. 2007; 24:2281-2296. [PubMed: 17939016]

38. Hasegawa M, Kusuhara H, Adachi M, Schuetz JD, Takeuchi K, Sugiyama Y. Multidrug resistanceassociated protein 4 is involved in the urinary excretion of hydrochlorothiazide and furosemide. J Am Soc Nephrol. 2007; 18:37-45. [PubMed: 17135398]

39. Schneider AG, Baldwin I, Freitag E, Glassford N, Bellomo R. Estimation of fluid status changes in critically ill patients: Fluid balance chart or electronic bed weight? J Crit Care. 2012; 27:745.e7-.e12. [PubMed: 22341728]

40. Perren A, Markmann M, Merlani G, Marone C, Merlani P. Fluid balance in critically ill patients. Should we really rely on it? Minerva Anestesiol. 2011; 77:802-811. [PubMed: 21730928]

41. Kociol RD, McNulty SE, Hernandez AF, Lee KL, Redfield MM, Tracy RP, et al. Markers of decongestion, dyspnea relief, and clinical outcomes among patients hospitalized with acute heart failure. Circ Heart Fail. 2013; 6:240-245. [PubMed: 23250981] 
42. Mega JL, Stitziel NO, Smith JG, Chasman DI, Caulfield MJ, Devlin JJ, et al. Genetic risk, coronary heart disease events, and the clinical benefit of statin therapy: an analysis of primary and secondary prevention trials. Lancet. 2015; 385:2264-2271. [PubMed: 25748612] 


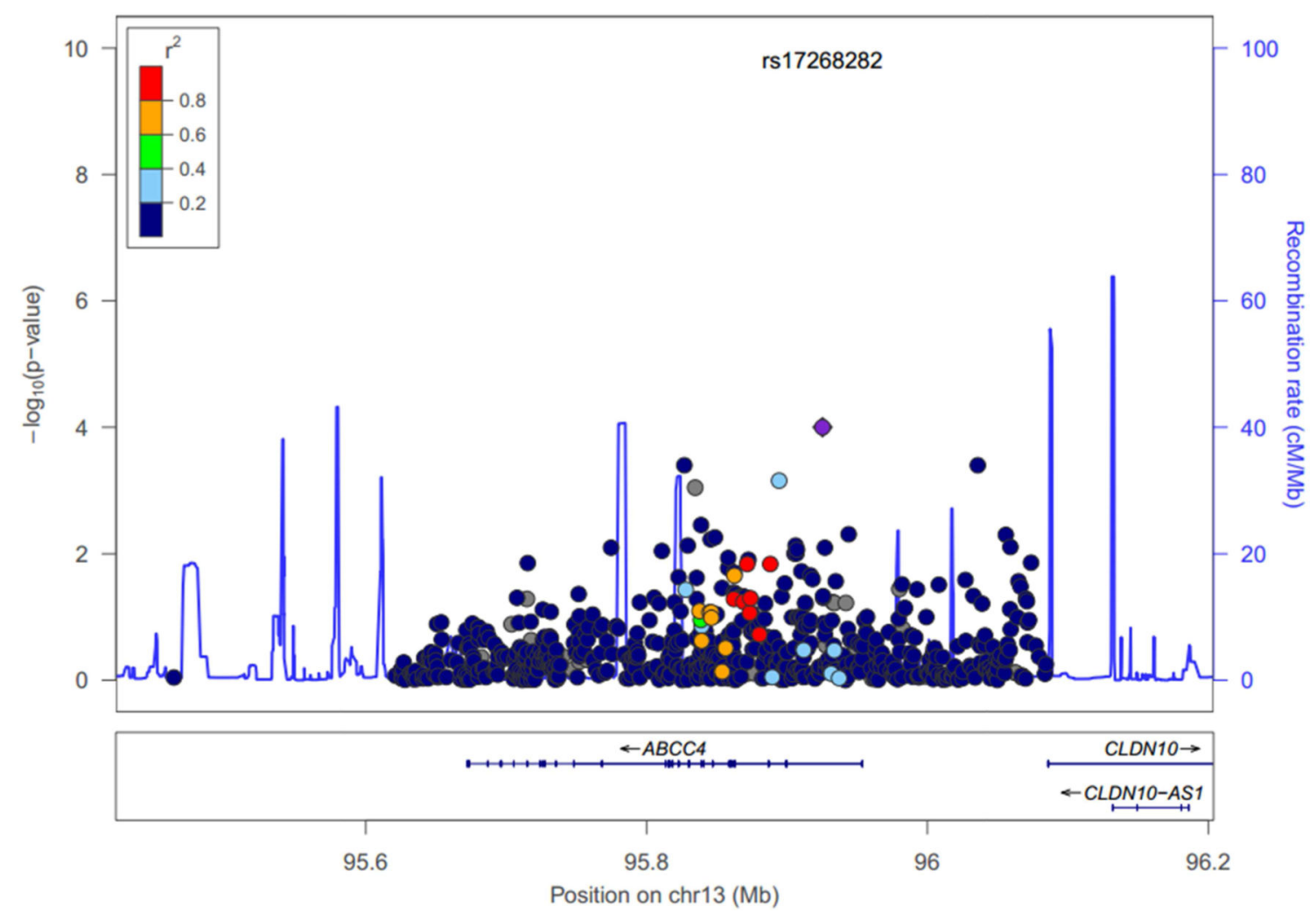

Figure 1.

Regional visualization of genetic association results in the region of gene $A B C C 4$ for weight loss. Negative $\log _{10}$ of random effects meta-analysis $P$ values are shown on the first $Y$ axis for SNPs with MAF $\searrow 0.01$. The second $y$-axis shows the recombination rate from HapMap reference samples (blue line). Genes are displayed below the SNPs, base pair positions are given according to hg 19, the degree of linkage disequilibrium $\left(\mathrm{r}^{2}\right)$ of each genetic variant with rs17268282 is displayed as dark blue for [0, 0.2], light blue for [0.2, 0.4], green for $[0.4,0.6]$, orange for $[0.6,0.8]$, red for $[0.8,1.0]$. 


\section{Table 1}

Candidate genes evaluated as part of the current substudy ${ }^{*}$

\begin{tabular}{|c|l|c|}
\hline Gene name & Gene function & Number of SNPs included in the analyses \\
\hline$S L C 12 A 1$ & Apical Na+K+2Cl- symporter & 94 \\
\hline$S L C 12 A 2$ & Basolateral Na+-K+-2Cl- symporter & 83 \\
\hline$S L C 12 A 3$ & Na+Cl- symport & 103 \\
\hline$S L C 22 A 6$ & Organic Anion transporter 1 & 45 \\
\hline$S L C 22 A 8$ & Organic Anion transporter 3 & 58 \\
\hline$U G T 1 A 1$ & Uridine diphosphate-glucuronosyltransferase-1 & $17^{\text {Il }}$ \\
\hline$U G T 1 A 8$ & Uridine diphosphate-glucuronosyltransferase-8 & $93^{7}$ \\
\hline$U G T 1 A 9$ & Uridine diphosphate-glucuronosyltransferase-9 & 2 \\
\hline$C L C N K B$ & Chloride channel & 23 \\
\hline$A B C C 2$ & ATP-binding cassette, sub-family C, member 2 & 120 \\
\hline$K C N J 1$ & Potassium inwardly-rectifying channel, subfamily J, member 1 & 106 \\
\hline$S C N N 1 A$ & Epithelial sodium channel $\alpha$-subunit & 65 \\
\hline$W N K 1$ & WNK lysine deficient protein kinase 1 & 110 \\
\hline$A B C C 4$ & ATP-binding cassette, sub-family C, member 4 & 811 \\
\hline$S C N N 1 B$ & Epithelial sodium channel $\beta$-subunit & 76 \\
\hline$S C N N 1 G$ & Epithelial sodium channel $\gamma$-subunit & 92 \\
\hline$C L C N K A$ & Chloride channel Ka & 18 \\
\hline$B S N D$ & Barttin & 73 \\
\hline$A P O L 1$ & Apolipoprotein L, 1 & 51 \\
\hline
\end{tabular}

* SNPs included in these analyses were selected from the custom Sequenom panels, the Sequenom iPLEX ADME PGx panel, the Illumina HumanExome chip and HumanOmni2.5 Beadchips. SNP: single nucleotide polymorphisms.

II Genes UGTA1, UGTA8 and UGTA9 are overlapping. Of the 17 SNPs, 13 are present in UGTA1, UGTA8 and UGTA9.

${ }^{*}$ Of the 93 SNPs 23 are present in UGTA8 and UGTA9 
Table 2

Baseline characteristics and medication use by study populations

\begin{tabular}{|c|c|c|c|c|}
\hline & All $(n=364)$ & CARRESS $(n=42)$ & DOSE $(n=60)$ & $\operatorname{ROSE}(n=262)$ \\
\hline \multicolumn{5}{|l|}{ Demographic data } \\
\hline Sex, male, n (\%) & $261(71.7)$ & $29(69.1)$ & $39(65.0)$ & $193(73.7)$ \\
\hline Age in yrs, mean \pm SD & $69.1 \pm 12.1$ & $65.3 \pm 13.1$ & $70.0 \pm 11.6$ & $69.5 \pm 12.0$ \\
\hline \multicolumn{5}{|l|}{ Race, n (\%) } \\
\hline White & $273(75.0)$ & $31(73.8)$ & $48(80.0)$ & $194(74.1)$ \\
\hline Black & $75(20.6)$ & $9(21.4)$ & $9(15.0)$ & $57(21.8)$ \\
\hline Other & $15(4.1)$ & $2(4.8)$ & $3(5.0)$ & $10(3.8)$ \\
\hline Ischemic etiology of HF, n (\%) & $209(57.4)$ & $20(47.6)$ & $39(65.0)$ & $150(57.3)$ \\
\hline $\mathrm{LVEF}, \%$,mean $\pm \mathrm{SD}$ & $36.2 \pm 17.2$ & $34.4 \pm 16.4$ & $34.9 \pm 18.8$ & $36.7 \pm 17.0$ \\
\hline LVEF $\$ 40 \%, \mathrm{n}(\%)$ & $225(61.8)$ & $28(66.7)$ & $38(63.3)$ & $159(60.7)$ \\
\hline NT-proBNP, pg/ml & $7449.7 \pm 8200.3$ & $6482.3 \pm 6343.2$ & $6787.9 \pm 6554.1$ & $7762.0 \pm 8792.8$ \\
\hline Atrial fibrillation / flutter, n (\%) & $214(58.8)$ & $22(52.4)$ & $37(61.7)$ & $155(59.2)$ \\
\hline Diabetes, n (\%) & $206(56.6)$ & $27(64.3)$ & $36(60.0)$ & $143(54.6)$ \\
\hline Weight, $\mathrm{kg}$ mean $\pm \mathrm{SD}$ & $97.7 \pm 28.2$ & $114.7 \pm 31.8$ & $94.8 \pm 26.7$ & $95.6 \pm 27.1$ \\
\hline BMI, $\mathrm{kg} / \mathrm{m}^{2}$ mean $\pm \mathrm{SD}$ & $33.3 \pm 8.9$ & $39.0 \pm 10.9$ & $33.2 \pm 8.6$ & $32.4 \pm 8.4$ \\
\hline $\mathrm{eGFR}, \mathrm{ml} / \mathrm{min} / 1.72 \mathrm{~m}^{2}$ & $42.5 \pm 16.5$ & $31.0 \pm 9.2$ & $51.9 \pm 24.1$ & $42.2 \pm 13.9$ \\
\hline \multicolumn{5}{|l|}{ Medication at baseline } \\
\hline ACE inhibitor or ARB, $\mathrm{n}(\%)$ & $195(53.6)$ & $25(59.5)$ & $36(60.0)$ & $134(51.2)$ \\
\hline Beta blocker, n (\%) & $311(85.4)$ & $34(81.0)$ & $53(88.3)$ & $224(85.5)$ \\
\hline Aldosterone antagonist, $\mathrm{n}(\%)$ & $114(31.3)$ & $12(28.6)$ & $21(35.0)$ & $81(30.9)$ \\
\hline Oral furosemide-eq dose before the hospitalization, $\mathrm{mg} /$ day & $190.1 \pm 256.9$ & $310.5 \pm 389.9$ & $169.2 \pm 123.6$ & $175.5 \pm 248.2$ \\
\hline Furosemide-eq IV dose in the 24 hours prior to randomization & $118.7 \pm 117.7$ & 183. $8 \pm 172.8$ & $92.3 \pm 102.2$ & $114.3 \pm 106.6$ \\
\hline \multicolumn{5}{|l|}{ Diuretic use during 72 hours after randomization } \\
\hline Furosemide-eq IV dose from randomization to $72 \mathrm{~h}, \mathrm{mg}$ & $643.6 \pm 419.3$ & $693.1 \pm 478.6$ & $687.2 \pm 367.9$ & $625.7 \pm 420.5$ \\
\hline Metolazone, n (\%) & $78(21.4)$ & $19(45.2)$ & $8(13.3)$ & $51(19.5)$ \\
\hline HCTZ/Chlorothiazide, n (\%) & $15(4.1)$ & $2(4.8)$ & $1(1.7)$ & $12(4.6)$ \\
\hline \multicolumn{5}{|l|}{ Diuretic response at 72 hours } \\
\hline Net fluid loss & $4650.4 \pm 3023.9$ & $5937.8 \pm 3690.1$ & $3639.7 \pm 2477.4$ & $4675.8 \pm 2946.9$ \\
\hline Weight loss & $-3.6 \pm 3.8$ & $-5.2 \pm 5.0$ & $-3.4 \pm 3.3$ & $-3.5 \pm 3.6$ \\
\hline \multicolumn{5}{|l|}{ Minor allele frequency of the primary SNPs of interest } \\
\hline \multicolumn{5}{|l|}{$S L C 12 A 3$} \\
\hline rs 1529927 & 0,026 & 0,048 & 0,042 & 0,017 \\
\hline \multicolumn{5}{|l|}{$S C N N 1 B 2$} \\
\hline rs 152728 & 0,358 & 0,451 & 0,333 & 0,341 \\
\hline rs 152745 & 0,5 & 0,596 & 0,458 & 0,489 \\
\hline rs 238547 & 0,353 & 0,262 & 0,358 & 0,368 \\
\hline \multicolumn{5}{|l|}{$S C N N 1 G$} \\
\hline rs5723 & 0,24 & 0,274 & 0,258 & 0,229 \\
\hline rs5729 & 0,24 & 0,274 & 0,258 & 0,229 \\
\hline
\end{tabular}

Pharmacogenomics J. Author manuscript; available in PMC 2017 March 24. 
ACE, angiotensin-converting enzyme; ARB, angiotensin II receptor blocker; BMI, body mass index; eGFR, estimated glomerular filtration rate; HCTZ, hydrochlorothiazide; LVEF, left ventricular ejection fraction; NT-proBNP, N-terminal proB-type natriuretic peptide. 


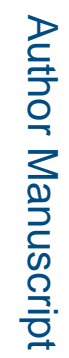

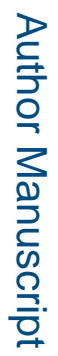

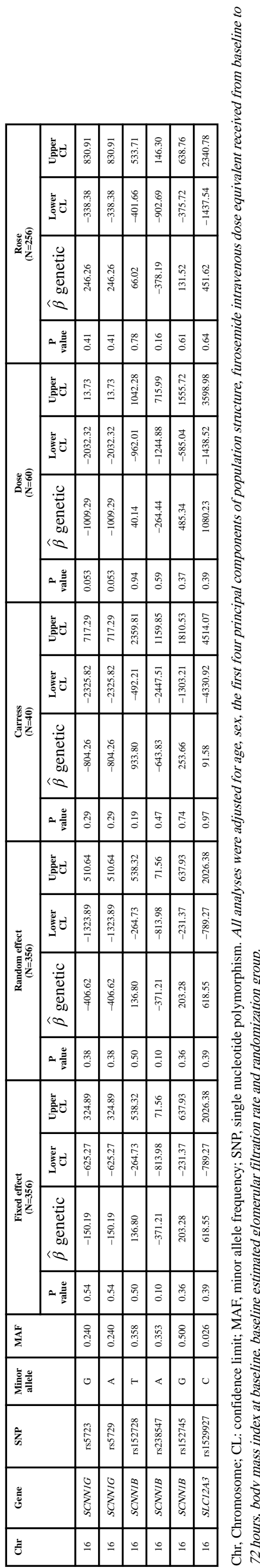

ᄅ 


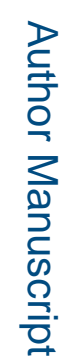
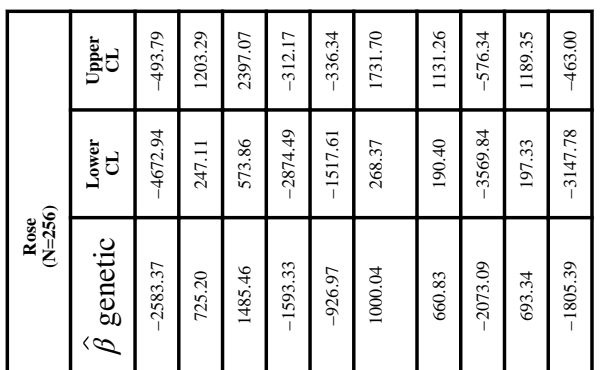

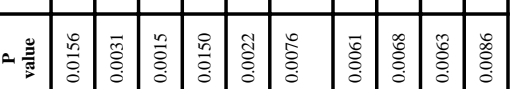

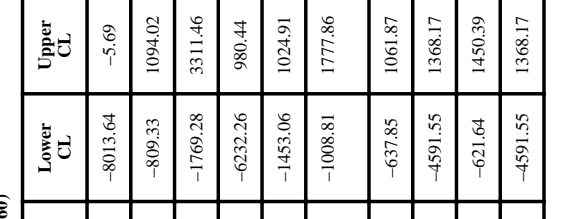

这衰

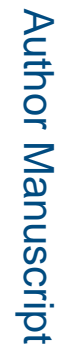

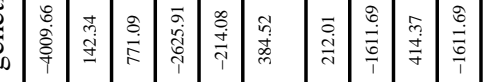

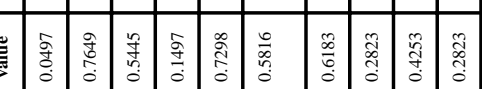

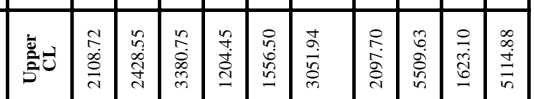

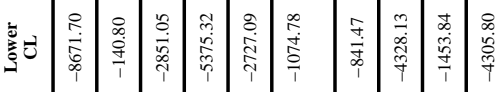

䱢高

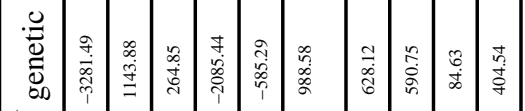

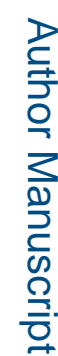
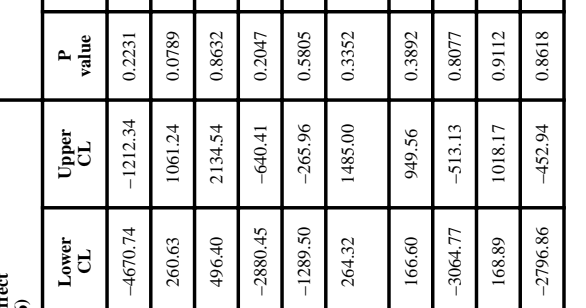

然
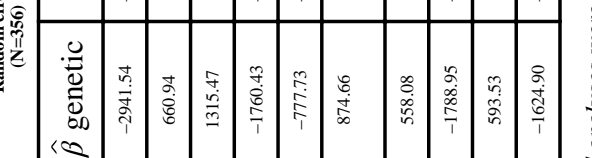

|

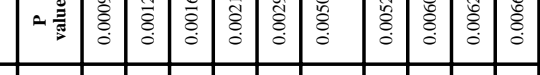

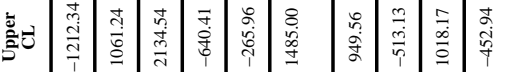

을
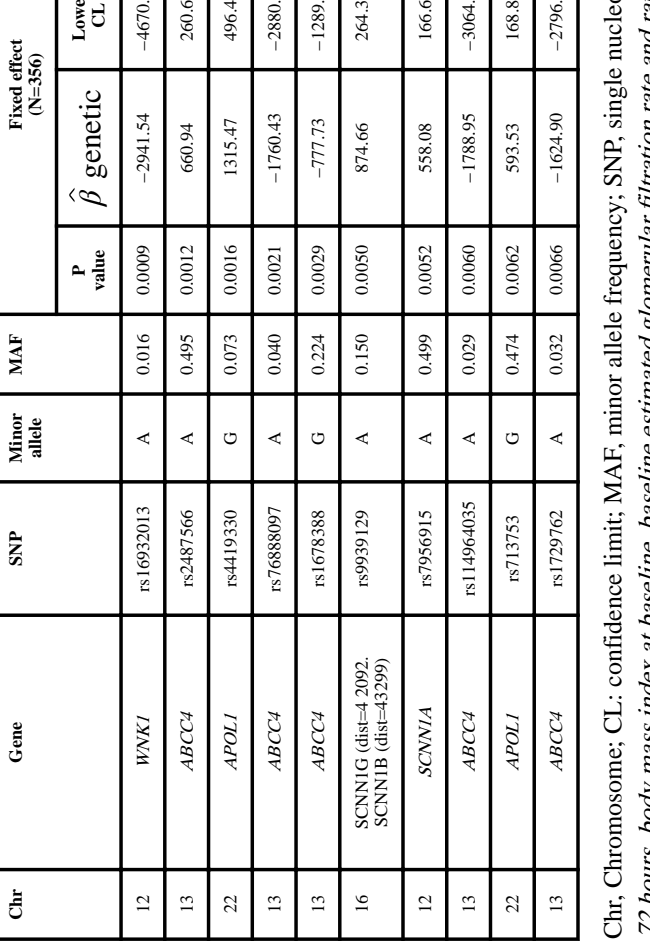


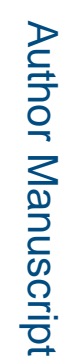

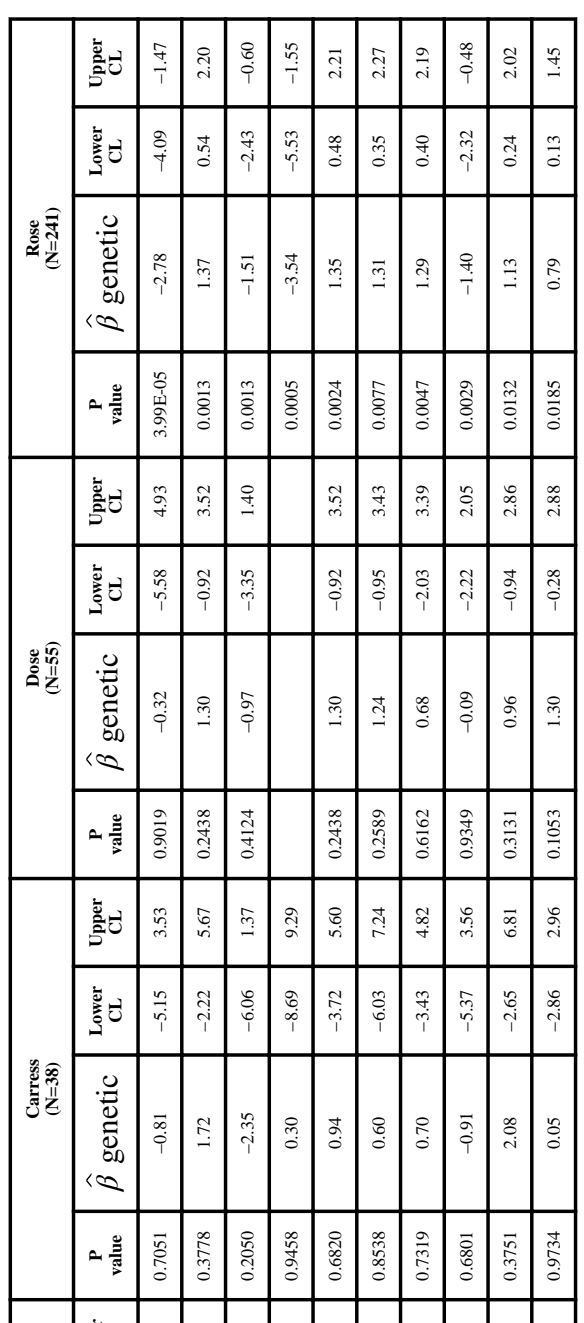

I

론

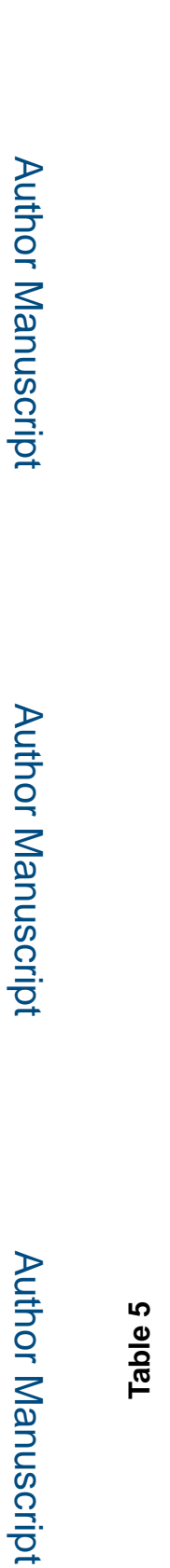

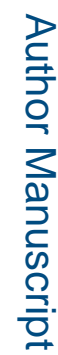

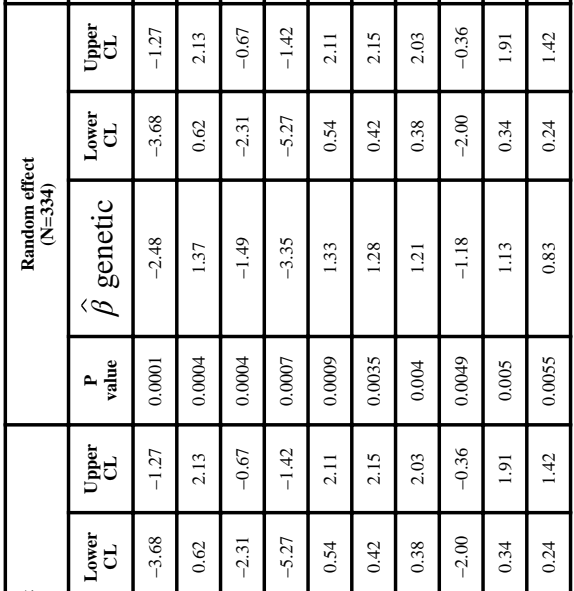

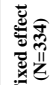
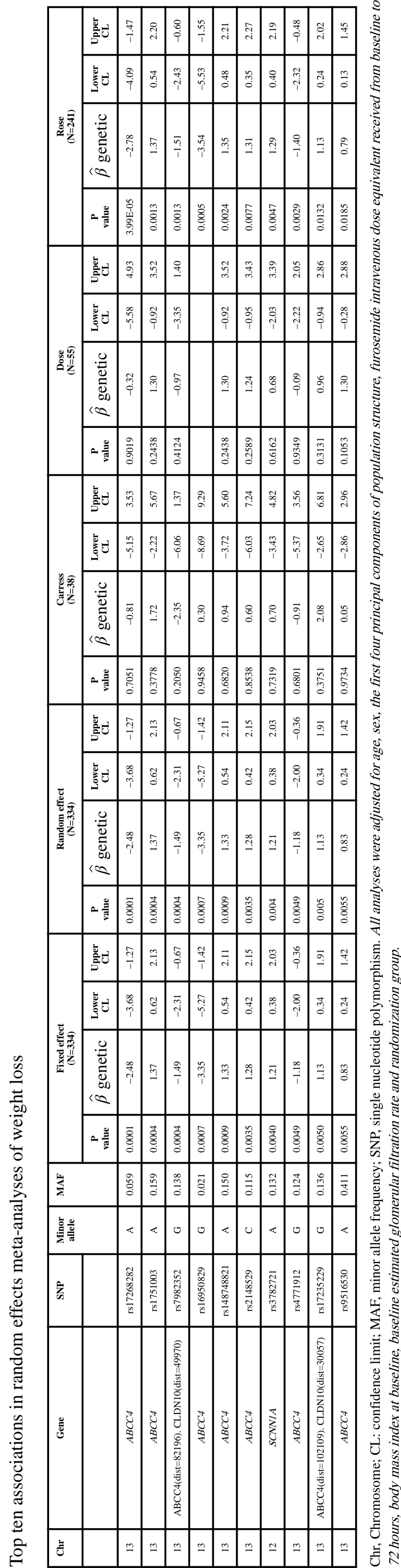


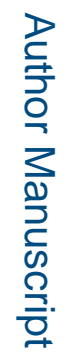

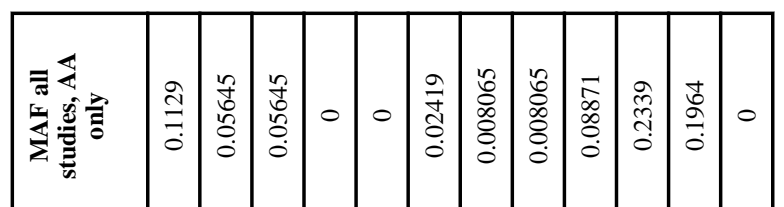

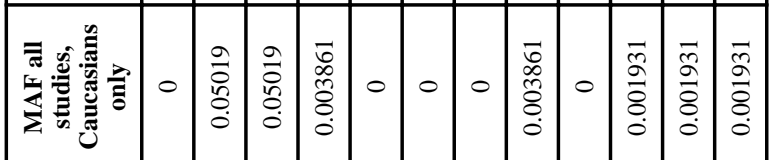

\begin{tabular}{|c|c|c|c|c|c|c|c|c|c|c|c|}
\hline 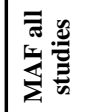 & 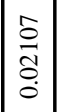 & \begin{tabular}{l}
0 \\
\hdashline \\
\multirow{2}{0}{} \\
0 \\
0
\end{tabular} & $\begin{array}{l}0 \\
\stackrel{0}{a} \\
\stackrel{0}{0} \\
0\end{array}$ & $\stackrel{+}{\circ}$ & 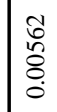 & 苛 & $\begin{array}{l}\vec{y} \\
\stackrel{5}{0} \\
\stackrel{0}{0}\end{array}$ & $\begin{array}{l}0 \\
0 \\
0 \\
0 \\
0 \\
0 \\
0\end{array}$ & $\begin{array}{l}\hat{\sigma} \\
\vec{\sigma} \\
0 \\
0\end{array}$ & & $\frac{t}{\Delta}$ \\
\hline
\end{tabular}

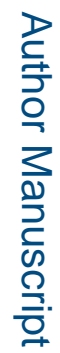

\begin{tabular}{|c|c|c|c|c|c|c|c|c|c|c|c|c|}
\hline 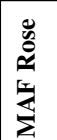 & $\begin{array}{l}\text { t. } \\
\stackrel{0}{0} \\
0\end{array}$ & 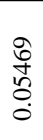 & $\begin{array}{l}0 \\
0 \\
+1 \\
0 \\
0 \\
0\end{array}$ & $\begin{array}{l}\frac{n}{2} \\
\frac{0}{0} \\
0\end{array}$ & $\begin{array}{l}\frac{n}{2} \\
\frac{0}{0} \\
0\end{array}$ & $\begin{array}{l}\infty \\
\infty \\
ٌ \\
0 \\
0 \\
0\end{array}$ & $\begin{array}{l}\stackrel{2}{a} \\
\overline{8} \\
0\end{array}$ & $\begin{array}{l}2 \\
\stackrel{0}{0} \\
0 \\
0\end{array}$ & 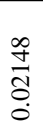 & 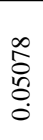 & $\overline{8}$ & 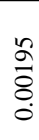 \\
\hline
\end{tabular}

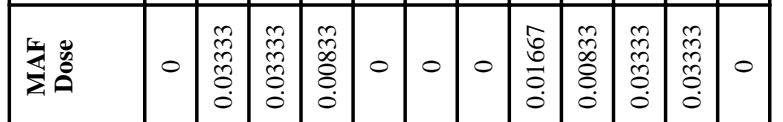

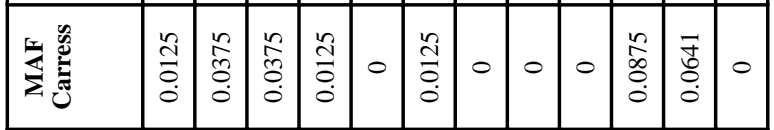

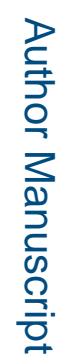

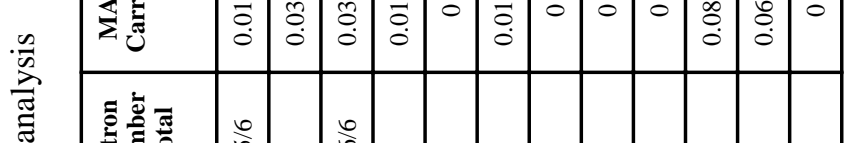

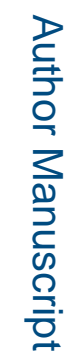

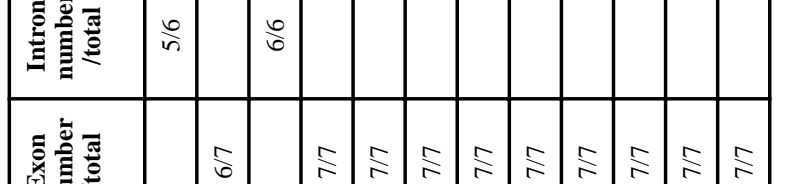

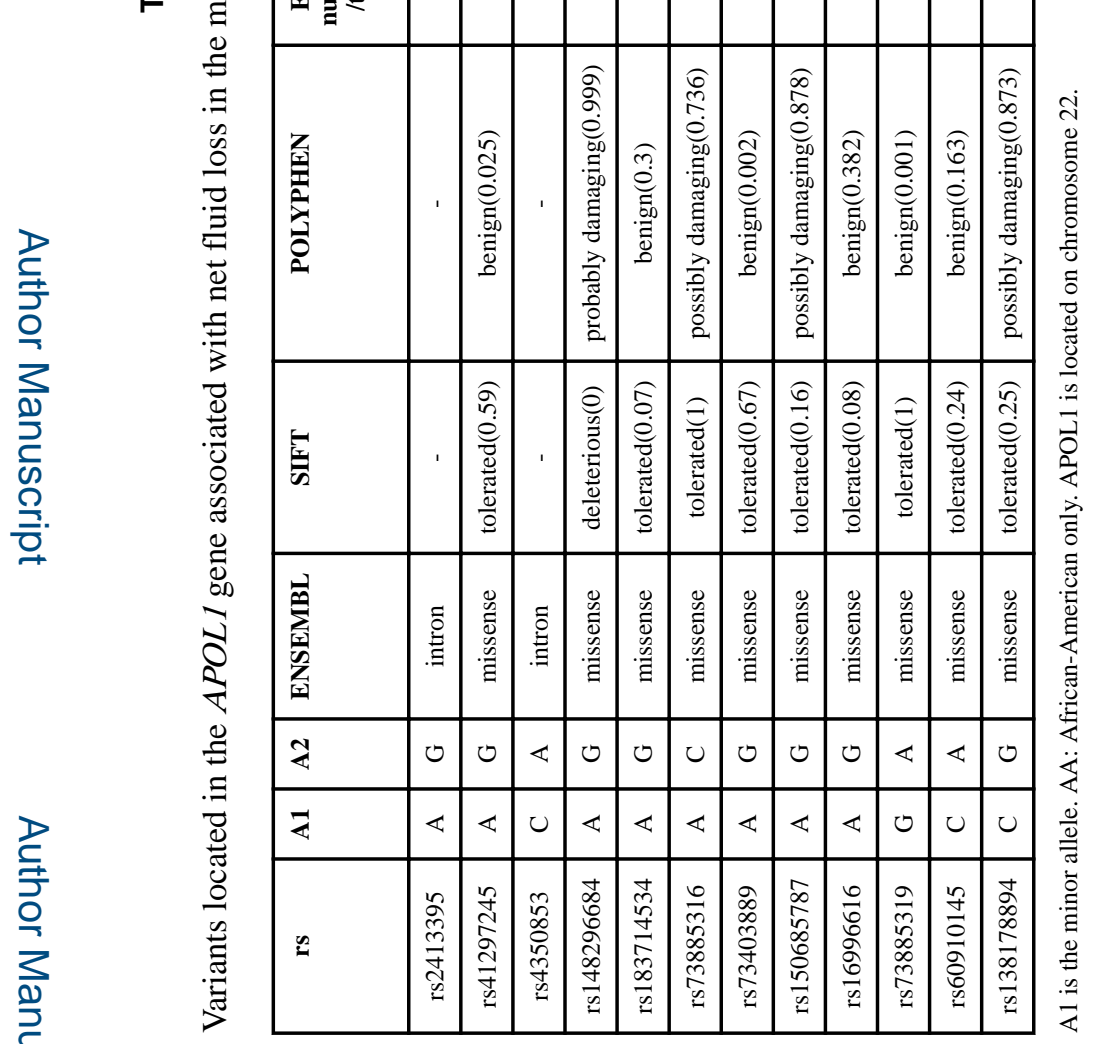

